\title{
ORIGINAL ARTICLE \\ Surgical compared with nonsurgical management of fractures in male veterans with chronic spinal cord injury
}

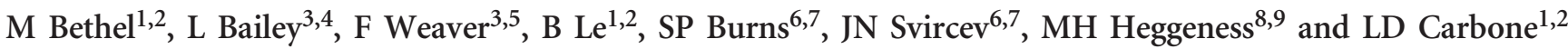

Study design: Retrospective review of a clinical database.

Objectives: To examine treatment modalities of incident appendicular fractures in men with chronic $\mathrm{SCl}$ and mortality outcomes by treatment modality.

Setting: United States Veterans Health Administration Healthcare System.

Methods: This was an observational study of 1979 incident fractures that occurred over 6 years among 12162 male veterans with traumatic SCl of at least 2 years duration from the Veterans Health Administration (VA) Spinal Cord Dysfunction Registry. Treatment modalities were classified as surgical or nonsurgical treatment. Mortality outcomes at 1 year following the incident fracture were determined by treatment modality.

Results: A total of 1281 male veterans with 1979 incident fractures met inclusion criteria for the study. These fractures included 345 (17.4\%) upper-extremity fractures and $1634(82.6 \%)$ lower-extremity fractures. A minority of patients $(9.4 \%)$ were treated with surgery. Amputations and disarticulations accounted for $19.7 \%$ of all surgeries ( $1.3 \%$ of all fractures), and the majority of these were done more than 6 weeks following the incident fracture. There were no significant differences in mortality among men with fractures treated surgically compared with those treated nonsurgically.

Conclusions: Currently, the majority of appendicular fractures in male patients with chronic $\mathrm{SCl}$ are managed nonsurgically within the VA health-care system. There is no difference in mortality by type of treatment.

Spinal Cord (2015) 53, 402-407; doi:10.1038/sc.2015.5; published online 27 January 2015

\section{INTRODUCTION}

As of 2012, there were an estimated 270000 individuals in the United States living with a traumatic spinal cord injury (SCI), and this number is expected to increase over time. ${ }^{1}$ Osteoporosis-related fractures are a frequent occurrence in SCI patients, as severe loss of bone mineral density of the long bones below the level of spinal injury occurs in nearly all of these patients, ${ }^{2,3}$ predisposing them to fracture with minor or no trauma. In addition, falls are a substantial risk factor for osteoporotic fractures in this population. ${ }^{4,5}$ The exact prevalence of fractures in the SCI population is not known, as some fractures go unrecognized; however, it was recently reported that in male veterans with SCI of at least 2 years duration, there is a 14\% 5-year incidence of lower-extremity fractures. ${ }^{6}$

Historically, most osteoporotic fractures in SCI patients have been treated conservatively, that is, with immobilization of the limb and not with surgical fixation. ${ }^{7-10}$ However, the studies describing this are 2-3 decades old, have limited sample sizes ${ }^{7-10}$ and may not reflect the advances in surgical techniques and nonsurgical treatments for fractures that are now available. ${ }^{11,12}$ The purpose of this study was to describe how fractures in patients with SCI are currently treated and to determine whether there were differences in mortality by type of fracture treatment.

\section{MATERIALS AND METHODS \\ Patients}

The VA spinal cord dysfunction (SCD) Registry is an administrative clinical database maintained by individual VA medical centers to track the population of veterans with SCD (including SCI) followed at each center. These data are also aggregated at a national level; therefore, the SCD Registry represents veterans with SCI/D across the United States. ${ }^{13}$ All males included in the SCD Registry from fiscal years 2002 to 2007 with a traumatic SCI of at least 2 years duration were eligible for the analyses. Only those having a SCI of a minimum of 2 years duration were included, as a new steady-state between bone resorption and bone formation is reached $\sim 18$ months to 2 years following SCI. ${ }^{14}$ Information on etiology, duration, level and completeness of the SCI was obtained from the Registry. Diagnoses were determined using VA medical SAS inpatient data sets and the outpatient care file.

The study was approved by the VA institutional review board and the principles of the declaration of Helsinki were followed.

\section{Incident fractures}

Fractures were defined using the International Statistical Classification of Diseases: 9th revision, Clinical Modification ${ }^{15}$ (ICD-9 codes, Table 1). All encounters within a 120-day time frame with the same 3-digit ICD-9 code were considered a single fracture. ${ }^{16}$ Pathological fractures (ICD-9 code 733 ), ill-defined fractures of the lower extremity (ICD-9 code 827.x) and

${ }^{1}$ Charlie Norwood Veterans Affairs Medical Center, Augusta, GA, USA; ${ }^{2}$ Department of Medicine, Georgia Regents University, Augusta, GA, USA; ${ }^{3}$ Center of Innovation for Complex Chronic Healthcare, Edward J. Hines, Jr. VA Hospital, Hines, IL, USA; ${ }^{4}$ Department of Epidemiology and Biostatistics, School of Public Health, University of Illinois at Chicago, Chicago, IL, USA; ${ }^{5}$ Stritch School of Medicine, Loyola University, Maywood, IL, USA; ${ }^{6}$ VA Puget Sound Health Care System-Seattle Division, Seattle, WA, USA; ${ }^{7}$ Department of Rehabilitation Medicine, University of Washington, Seattle, WA, USA; ${ }^{8}$ Robert J. Dole Veterans Affairs Medical Center, Wichita, KS, USA and ${ }^{9}$ Department of Orthopaedic Surgery, University of Kansas School of Medicine, Wichita, KS, USA

Correspondence: Dr M Bethel, Charlie Norwood Veterans Affairs Medical Center, 950 15th Street, Augusta, GA 30912, USA

E-mail: mbethe|@gru.edu

Received 23 September 2014; revised 11 December 2014; accepted 18 December 2014; published online 27 January 2015 
Table 1 ICD-9 codes for appendicular fractures identified in the study sample

\begin{tabular}{lc}
\hline Fracture site & ICD-9 code \\
\hline Clavicle & $810 . x$ \\
Scapula & $811 . x$ \\
Humerus & $812 . x$ \\
Forearm & $813 . x$ \\
Carpal & $814 . x$ \\
Metacarpal & $815 . x$ \\
Phalanges of hand & $816 . x$ \\
Multiple fractures of hand & $817 . x$ \\
Pelvis & $808 . x$ \\
Femoral neck & $820.1 x, 820.8,820.9$ \\
Trochanteric & $820.20,820.30$ \\
Intertrochanteric & $820.21,820.31$ \\
Subtrochanteric & $820.22,820.32$ \\
Femur & $821 . x$ \\
Patella & $822 . x$ \\
Tibia/Fibula & $823 . x$ \\
Ankle & $824 . x$ \\
Tarsals/metatarsals & $825 . x$ \\
Phalanges of foot & $826 . x$ \\
\hline
\end{tabular}

Table 2 Surgical treatment for fractures

\begin{tabular}{lc}
\hline Procedure description & ICD-9 Code \\
\hline External fixation & $78.1 \mathrm{x}$ \\
Open reduction with internal fixation & $78.5 x, 79.1 x, 79.2 x, 79.3 x$ \\
Total hip replacement & 81.51 \\
Partial hip replacement & 81.52 \\
Total shoulder replacement & 81.80 \\
Partial shoulder replacement & 81.81 \\
\hline
\end{tabular}

site-unspecified (ICD-9 code 829.x) fractures were excluded. Fractures from high-energy external injuries ('E-coded'17) were excluded except for those from accidental falls (E888.9), which were described separately. Finally, multiple fractures (having unique ICD-9 codes) recorded on the same day were excluded, because, in a subsample chart review, it could be confirmed that these were indeed multiple unique fractures occurring on the same day in only $10 \%$ of patients.

\section{Fracture treatment}

ICD-9 codes for surgical treatment of fractures are listed in Table 2. A fracture was considered to be nonsurgically managed if there were no ICD-9 codes present for surgical treatment of a fracture within the first year following the incident fracture.

For the primary analyses, three major groups were defined: single upperextremity fracture, single lower-extremity fracture and multiple fractures (more than one site-specific fracture on a unique day in the study-eligible time period). There is no exact definition in the literature to define time points for primary surgical management versus nonsurgical management of a fracture. For the purposes of this study, a fracture was considered to be surgically managed if an appropriate ICD-9 code for a surgical treatment was present up to 1 year after the incident fracture.

All surgical fracture codes identified in the 1-year period following the fracture were captured. The surgery most proximate to the fracture date was considered as the fracture surgery, if it was consistent with surgical techniques for management of that specific fracture. All surgical codes were reviewed in detail by the orthopedic surgeon on this project. For individuals with multiple fractures within the 6-year study window, baseline characteristics are presented for the patients' first fracture. Mortality is calculated from the last incident fracture.

Finally, the association between heterotopic ossification (HO) and treatment modality was explored. HO is a common complication in SCI, particularly around the hip joint, ${ }^{18}$ and has been associated with the formation of contractures $^{19}$ and pressure ulcers. ${ }^{20} \mathrm{HO}$ has been reported to occur after fractures in SCI, although the mechanism is not fully understood. ${ }^{21-23}$ The diagnosis of $\mathrm{HO}$ was identified for up to 1 year following an incident fracture (ICD-9 code $728.1 \mathrm{x}$ ), as HO may have necessitated surgery in a fracture that was initially nonsurgically managed.

\section{Statistical analysis}

Bivariate analyses of baseline characteristics of patients were analyzed using $\chi^{2}$-tests (or Fisher's exact test) for categorical variables and analysis of variance (ANOVA) for continuous variables. The frequency of surgical and nonsurgical management by fracture site is described. $\chi^{2}$ analysis was used to determine differences in mortality among fracture groups and between surgically and nonsurgically treated fractures. Statistical significance was set at an alpha equal to or less than 0.05 .

\section{RESULTS}

Within the VA SCD Registry, there were 12162 eligible male veterans with a traumatic SCI of at least 2 years duration from fiscal years 2002-2007. The final analysis group included 1979 site-specific fractures in 1281 unique patients (Figure 1). There were 1634 lower-extremity fractures (82.6\%) and 345 (17.4\%) upper-extremity fractures. The most common upper-extremity fracture site was the humerus, accounting for $27.8 \%$ of all upper-extremity fractures (Table 3). In the lower extremity, the most common fracture sites (Table 3) were the tibia/fibula (33.2\%), the femur (25.6\%) and the hip $(15.5 \%)$. Hip fractures included fractures of the femoral neck, trochanteric, intertrochanteric and subtrochanteric regions of the femur but did not include pelvic fractures.

Descriptive statistics for the patient sample by group and fracture treatment are shown in Table 4. There were no significant differences in age $(P \geqslant 0.38)$, race $(P \geqslant 0.70)$, extent $(P \geqslant 0.35)$ and duration $(P \geqslant 0.12)$ of SCI, and Charlson comorbidity indices $(P \geqslant 0.11)$ among the patients with a single upper-extremity fracture, single lower-extremity fracture or multiple fractures based on treatment modality (surgical versus nonsurgical). There was a significant difference in level of SCI in those with single lower-extremity fractures based on treatment modality (Table 3, $P=0.04)$.

A minority of patients $(n=121,9.4 \%)$ and fractures $(n=127$, $6.4 \%$ ) were treated with surgery; 132 surgical procedures were performed. Among specific fracture sites, hip fractures were the most common fracture site treated with surgery (35 of 253 fractures; $13.2 \%$ ), followed by femur fractures (45 of 419 femur fractures; $10.7 \%)$. The most common upper-extremity fractures to be treated with surgery were humerus fractures (7 of 96 humerus fractures, 7.3\%) (Table 3).

Tables $5 \mathrm{~A}$ and $5 \mathrm{~B}$, detail the type of surgery by fracture location. Open reduction with internal fixation (ORIF) was most common surgical procedure performed overall and accounted for 95 (72.0\%) of the 132 surgical treatments.

Amputations and disarticulations occurred in only 25 of 1979 fracture events (1.3\%). Amputations and disarticulations were most commonly done (in 75\% of cases) more than 6 weeks following the incident fracture. There were 26 amputations and disarticulations among 24 patients. Of the 22 patients who only had a single amputation or disarticulation of the lower extremity, 
the distribution of fracture sites was as follows: above-the-knee amputations (AKAs) followed two femoral neck fractures, one intertrochanteric fracture, nine femur fractures, four tibia/fibula fractures and one ankle fracture; below-the-knee amputations (BKA) followed four tibia/fibula fractures; one disarticulation followed a femur fracture.

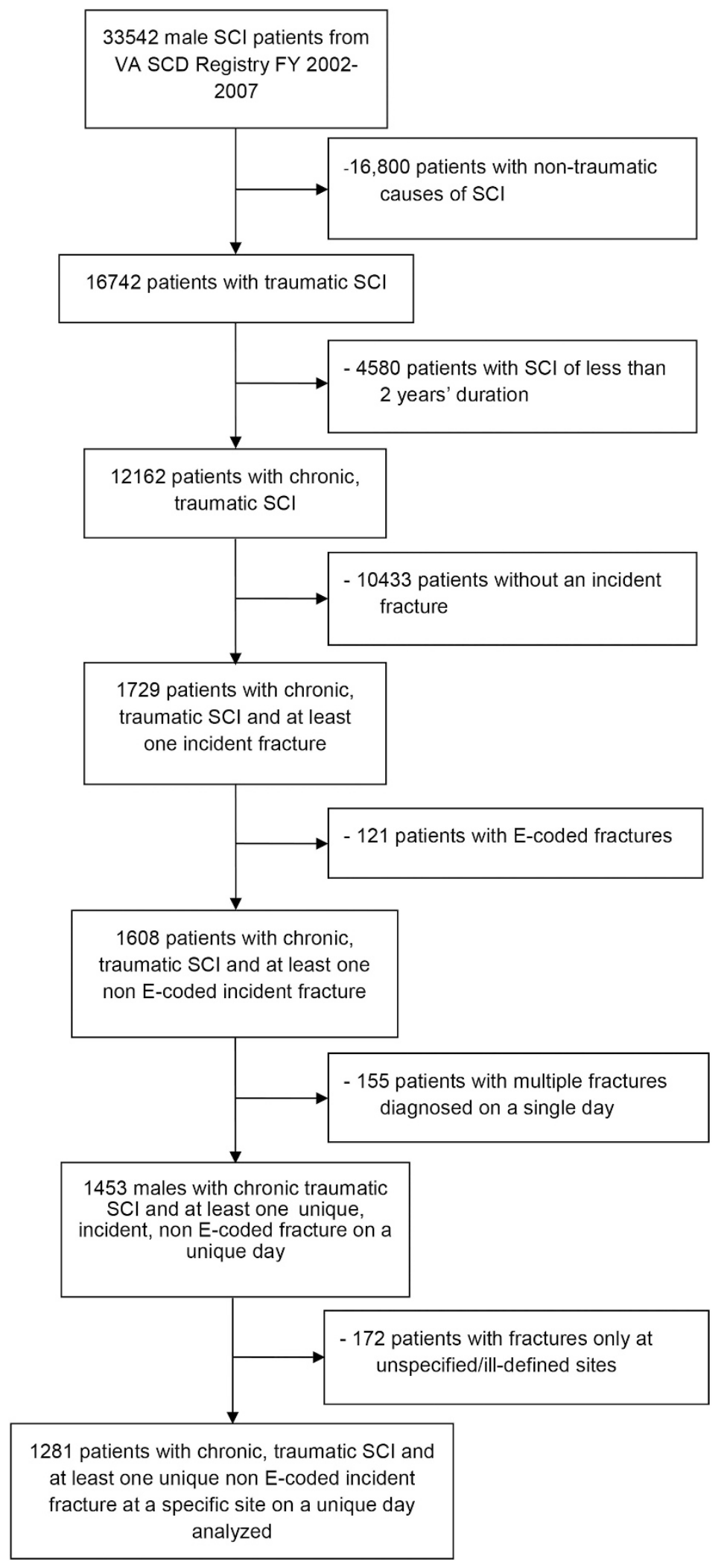

Figure 1 Study sample. 
Table 3 Fracture treatment by fracture site

\begin{tabular}{|c|c|c|c|}
\hline \multirow[t]{2}{*}{ Fracture site } & \multirow[t]{2}{*}{ n (\%) } & \multicolumn{2}{|c|}{ Treatment } \\
\hline & & Surgical & Nonsurgical \\
\hline Upper extremity & $345(17.4)$ & $15(4.3)$ & $330(95.7)$ \\
\hline Scapula & $3(0.9)$ & $0(0.0)$ & $3(100.0)$ \\
\hline Clavicle & $38(11.0)$ & $1(2.6)$ & $37(97.4)$ \\
\hline Humerus & $96(27.8)$ & $7(7.3)$ & $89(92.7)$ \\
\hline Forearm & 55 (15.9) & $3(5.5)$ & $52(94.5)$ \\
\hline Carpal & $42(12.2)$ & $1(2.4)$ & $41(97.6)$ \\
\hline Metacarpal & $59(17.1)$ & $1(1.7)$ & $58(98.3)$ \\
\hline Phalanges of hand & $51(14.8)$ & $2(3.9)$ & $49(96.1)$ \\
\hline Multiple hand & $1(0.3)$ & $0(0.0)$ & $1(100.0)$ \\
\hline Lower extremity & $1634(82.6)$ & 112 (6.9) & 1522 (93.1) \\
\hline Pelvis & $39(2.4)$ & $4(10.3)$ & 35 (89.7) \\
\hline All hip & 253 (15.5) & $34(13.4)$ & 219 (86.6) \\
\hline Femoral neck & 169 (10.3) & $27(16.0)$ & $142(84.0)$ \\
\hline Trochanteric & $18(1.1)$ & $1(5.9)$ & $17(94.1)$ \\
\hline Intertrochanteric & $10(0.6)$ & $1(10.0)$ & $9(90.0)$ \\
\hline Subtrochanteric & $56(3.4)$ & $5(8.9)$ & $51(91.1)$ \\
\hline Femur & 419 (25.6) & $43(10.2)$ & 376 (89.7) \\
\hline Patella & $26(1.6)$ & $0(0.0)$ & 26 (100.0) \\
\hline Tibia/fibula & $542(33.2)$ & $22(4.1)$ & $520(95.9)$ \\
\hline Ankle & $206(12.6)$ & $6(2.9)$ & $200(97.1)$ \\
\hline Tarsal/metatarsal & $105(6.4)$ & $2(1.9)$ & $103(98.1)$ \\
\hline Phalanges of foot & $44(2.7)$ & $1(2.3)$ & 43 (97.7) \\
\hline All Fractures & 1979 (100.0) & $127(6.4)$ & 1852 (93.6) \\
\hline
\end{tabular}

There were two additional amputations including one finger amputation and one toe amputation. All but one amputation or disarticulation (a finger amputation) was associated with lowerextremity fractures as detailed above.

One patient had an AKA 13 days post fracture, followed by a disarticulation of the hip 28 days later related to the same trochanteric fracture. Another patient experienced two AKAs from two distinct incident fractures, one of the femur and another of the tibia/fibula. The femur was the most common fracture site to undergo an amputation or disarticulation $(n=10 ; 7.9 \%$ of all surgically treated fractures, Table 5B). The two disarticulations followed a trochanteric fracture and a femoral shaft fracture. Surgical codes before amputations were very rare, with only one amputation (an AKA) preceded by a surgical code for a primary fracture treatment (an ORIF, data not shown). Amputations and disarticulations were more common in patients with diabetes compared with those without (37.5 versus $14.6 \%, P=0.14$ ), a difference that while not statistically significant, may be clinically significant. Fifty percent of the patients undergoing an amputation had multiple fractures within the study period.

Arthroplasties were rarely performed (7 of 132 surgeries, 5.3\%). Further examination of surgical therapies revealed that for hip fracture cases, arthroplasties were only performed for femoral neck fracture sites (4 of 169 femoral neck fractures, 2.4\%).

There were few (forty-eight) E-coded fractures for accidental falls. Most commonly, accidental falls resulted in fractures of the tibia/ fibula.

Over a 1-year period following the last incident fracture there were 94 deaths in the cohort; $6(5.0 \%)$ in the surgically treated group and $88(7.6 \%)$ in the nonsurgically treated group, a difference that was not statistically significant $(P=0.71)$.
Table 4 Baseline characteristics of patients by treatment

\begin{tabular}{|c|c|c|c|}
\hline \multirow[t]{2}{*}{ Fracture site } & \multicolumn{3}{|c|}{ Treatment } \\
\hline & Surgical & Nonsurgical & P-value ${ }^{a}$ \\
\hline Upper extremity $(\mathrm{n}=183)$ & $(n=6)$ & $(n=177)$ & \\
\hline Age (years), mean \pm s.d. & $57.1 \pm 10.4$ & $56.2 \pm 12.4^{b}$ & 0.86 \\
\hline Race, $n(\%)$ & & & $>0.99$ \\
\hline White & $4(3.7)$ & $102(96.2)$ & \\
\hline Black & $0(0.0)$ & $21(100.0)$ & \\
\hline Other & $0(0.0)$ & $1(100.0)$ & \\
\hline Missing & $2(3.6)$ & $53(96.4)$ & \\
\hline Level of injury, $n(\%)$ & & & 0.87 \\
\hline Paraplegia & $3(4.0)$ & $72(96.0)$ & \\
\hline Tetraplegia & $2(2.6)$ & $75(97.4)$ & \\
\hline Unknown & $1(3.2)$ & $30(96.8)$ & \\
\hline Extent of injury, $n(\%)$ & & & 0.73 \\
\hline Complete & $0(0.0)$ & $29(100.0)$ & \\
\hline Incomplete & $4(3.9)$ & $98(96.1)$ & \\
\hline Missing & $2(3.8)$ & $50(96.2)$ & \\
\hline Duration of injury (years), mean \pm s.d. & $29.3 \pm 12.8$ & $20.7 \pm 12.9$ & 0.12 \\
\hline Charlson comorbidity index, ${ }^{\mathrm{C}}$ mean \pm s.d. & $4.2 \pm 3.9$ & $1.1 \pm 1.9$ & 0.11 \\
\hline Lower extremity $(n=664)$ & $(n=44)$ & $(n=620)$ & \\
\hline Age (years), mean \pm s.d. & $55.1 \pm 14.3$ & $56.7 \pm 12.1^{d}$ & 0.38 \\
\hline Race, $n(\%)$ & & & 0.70 \\
\hline White & $24(6.2)$ & $363(93.8)$ & \\
\hline Black & $6(7.9)$ & $70(92.1)$ & \\
\hline Other & $0(0.0)$ & $4(100.0)$ & \\
\hline Missing & $11(5.6)$ & $186(94.4)$ & \\
\hline Level of injury, $n(\%)$ & & & 0.04 \\
\hline Paraplegia & $30(7.4)$ & $351(92.7)$ & \\
\hline Tetraplegia & $10(3.6)$ & $242(96.4)$ & \\
\hline Unknown & 4 (12.9) & $27(87.1)$ & \\
\hline Extent of injury, $n(\%)$ & & & 0.35 \\
\hline Complete & $19(6.6)$ & $268(93.4)$ & \\
\hline Incomplete & $13(4.1)$ & 233 (95.9) & \\
\hline Missing & $12(9.1)$ & $119(90.8)$ & \\
\hline Duration of injury (years), mean \pm s.d. & $21.7 \pm 14.0$ & $24.3 \pm 14.2$ & 0.25 \\
\hline Charlson comorbidity index, ${ }^{\mathrm{c}}$ mean \pm s.d. & $1.0 \pm 1.7$ & $0.86 \pm 1.9$ & 0.57 \\
\hline Multiple fractures $(n=434)$ & $(n=41)$ & $(n=393)$ & \\
\hline Age (years), mean \pm s.d. & $57.3 \pm 12.4$ & $56.5 \pm 11.6$ & 0.65 \\
\hline Race, $n(\%)$ & & & 0.74 \\
\hline White & $26(10.0)$ & $236(90.1)$ & \\
\hline Black & $2(4.9)$ & $39(95.1)$ & \\
\hline Other & $0(0.0)$ & $4(100.0)$ & \\
\hline Missing & $11(8.7)$ & $116(91.3)$ & \\
\hline Level of injury, $n(\%)$ & & & 0.15 \\
\hline Paraplegia & $29(11.4)$ & $226(88.6)$ & \\
\hline Tetraplegia & $8(4.2)$ & $135(95.8)$ & \\
\hline Unknown & $4(11.1)$ & $32(88.9)$ & \\
\hline Extent of injury, $n(\%)$ & & & 0.89 \\
\hline Complete & $15(8.4)$ & $153(91.7)$ & \\
\hline Incomplete & $18(7.7)$ & $157(90.3)$ & \\
\hline Missing & $8(8.8)$ & $83(91.2)$ & \\
\hline Duration of injury (years), mean \pm s.d. & $25.1 \pm 14.0$ & $24.3 \pm 13.5$ & 0.74 \\
\hline Charlson comorbidity index, ${ }^{\mathrm{c}}$ mean \pm s.d. & $0.68 \pm 1.4$ & $0.73 \pm 1.5$ & 0.84 \\
\hline $\begin{array}{l}\text { All three fracture groups, } \chi^{2} \text {-test } \\
(3 \times 2 \text { contingency table })\end{array}$ & & & 0.02 \\
\hline
\end{tabular}

aANOVA for continuous variables, $\chi^{2}$-/Fisher's exact test for categorical variables. ${ }^{b} n=176$. 'Does not include index component for paraplegia/tetraplegia. ${ }^{d} n=618$. 
There were no ICD-9 codes for HO identified in the year following an incident fracture in any patient.

\section{DISCUSSION}

Male veterans with chronic SCI had a substantial number of appendicular fractures. In this series, the majority of fractures occurred in the lower extremity, which is in accord with the distribution of fractures reported in previous literature. ${ }^{16,24}$ A minority of patients, 9.4\%, received surgical treatment for a fracture, and this was most common for fractures at the hip. Amputations and disarticulations accounted for $\sim 20 \%$ of surgical treatments performed for fractures, though these occurred in $<2 \%$ of all fracture events.

Despite advances in surgical treatments for fractures, ${ }^{11,12,25}$ surgeries for appendicular fractures were rarely performed in this series. In another study of chronic SCI patients with femur and hip fractures by Bishop et al., ${ }^{26}$ nonsurgical treatments were also more commonly done than surgical treatments for femur and hip fractures, although surgical treatments were more commonly reported (37\% versus $9.4 \%$ ) than in this cohort. The series described here differs from the Bishop report $^{26}$ in a number of important ways. First, both primary and secondary diagnostic codes were used (only 218 (32.4\%) of the femur and hip fractures were classified as the primary diagnoses); second, inpatient and outpatient encounters with fracture codes were used; and last, only those with a traumatic etiology of SCI were included. In contrast, the series by Bishop et al. ${ }^{26}$ examined only inpatients with a primary diagnostic code for a fracture and included both traumatic

Table 5A Surgical procedures by fracture location - upper extremity

\begin{tabular}{c} 
Upper extremity \\
\cline { 2 - 4 } Procedure Clavicle Humerus Forearm Carpal Metacarpals Phalanges \\
\cline { 3 - 4 }
\end{tabular}

\begin{tabular}{|c|c|c|c|c|c|c|}
\hline ORIF & 1 & 6 & 3 & 1 & 1 & 1 \\
\hline Arthroplasty & - & 1 & - & - & - & - \\
\hline AKA & - & - & - & - & - & - \\
\hline BKA & - & - & - & - & - & - \\
\hline $\begin{array}{l}\text { Other amputa- } \\
\text { tion (digital) }\end{array}$ & - & - & - & - & - & 1 \\
\hline Disarticulation & - & - & - & - & - & - \\
\hline $\begin{array}{l}\text { External } \\
\text { fixation }\end{array}$ & - & - & - & - & - & - \\
\hline Total & 1 & 7 & 3 & 1 & 1 & 2 \\
\hline
\end{tabular}

Abbreviations: AKA, above-the-knee amputation; BKA, below-the-knee amputation; ORIF, open reduction with internal fixation. and nontraumatic etiologies of an SCI. ${ }^{26}$ The inclusion of nontraumatic SCI in this prior study ${ }^{26}$ may partially account for the greater frequency of surgeries reported because it is possible that fractures in nontraumatic SCI may be managed more like those in the general population.

In older studies, there was evidence that compared with more conservative measures, open surgical treatment of fractures in the setting of SCI might be associated with serious complications. ${ }^{7,27-29}$ The findings here suggest that this remains a common approach to fracture management today. Similar to hip fracture management outside of SCI, where hip fractures are almost always treated surgically, ${ }^{30,31}$ in this series, hip fractures were the most common fracture site to receive surgery.

A substantial percentage of the surgical procedures performed, particularly following femur fractures, were amputations. Amputations in this series were most commonly done more than 6 weeks following the fracture. Only one of the amputations was preceded by a surgical procedure code, an ORIF. Taken together, these findings suggest that limb-loss procedures more often than not were necessitated by unsuccessful nonsurgical treatments. In support of this, others have reported that nonsurgical treatment of fractures may be associated with complications ${ }^{7,27-29}$ and have observed good outcomes with primary surgical treatments. ${ }^{32}$ In addition, several studies have suggested that surgical treatment of fractures in SCI patients may expedite post-fracture mobilization. ${ }^{26,32}$ Conversely, other reports ${ }^{9,28,33,34}$ have found nonsurgical treatments to be effective.

The exact reasons for amputations following nonsurgical treatment in this series are not known; however, they were not done for $\mathrm{HO}$, as no patients in this series carried this diagnosis in the 1-year time period following the fracture.

There were no significant differences in mortality in surgically treated compared with nonsurgically treated fractures in this series. In accord with these findings, the Bishop repor $\mathrm{t}^{26}$ of chronic SCI patients with hip and femur fractures also found no significant differences in mortality rates among those treated surgically versus nonsurgically.

There were several limitations to this study. Fracture treatment that may have occurred outside of the VA health-care system was not captured. There were a large number of fractures occurring at unspecified and ill-defined sites (485 of 2464 fractures initially identified in the cohort, 19.7\%); the effects of excluding these fractures are not known. The reasons why a fracture may have failed initial nonsurgical treatment were not ascertained. Women represented only $3.0 \%$ of the VA SCD population and were therefore excluded to minimize heterogeneity in our sample. ASIA impairment scores were not included among the administrative data, nor was ambulatory

Table 5B Surgical procedures by fracture location - lower extremity

Procedure

Lower-extremity fracture sites

Pelvis Femoral neck Trochanteric Intertrochanteric Subtrochanteric Femur Tibia/fibula Ankle Tarsals/metatarsals Phalanges of foot

\begin{tabular}{lcccccccccc}
\hline ORIF & 3 & 21 & - & - & 5 & 34 & 11 & 6 & 2 \\
Arthroplasty & - & 4 & - & - & - & 2 & - & - & - & - \\
AKA & - & 2 & 1 & 1 & - & 9 & 4 & 1 & - \\
BKA & - & - & - & - & - & - & 4 & - & - & - \\
Other Amputation (digital) & - & - & - & - & - & - & - & - & - & - \\
Disarticulation & - & - & 1 & - & - & 1 & - & - & - & - \\
External Fixation & - & - & - & - & - & - & 4 & - & - \\
Total & 3 & 27 & 2 & 1 & 5 & 46 & 23 & 7 & 2 & 1 \\
\hline
\end{tabular}

Abbreviations: AKA, above-the-knee amputation; BKA, below-the-knee amputation; ORIF, open reduction with internal fixation. 
status. It is recognized that there may be differences in the incidence and the distribution of fractures in chronic SCI based on gender. ${ }^{24,35}$ The sample of surgically managed fractures was small, limiting our ability to infer success or failure of surgical intervention. Finally, in the statistical analysis, no adjustments were done to account for multiple testing.

Despite these limitations, there are a number of important strengths to this study. First, this is the largest series to date to examine treatment patterns following fracture in patients with SCI including both timing of surgery and type of surgical procedure done. More importantly, it indicates the need for prospective studies to determine the optimal treatment by fracture site in patients with chronic SCI.

In conclusion, appendicular fractures in SCI patients are frequent events and are rarely managed surgically within the VA health-care system. Prospective assessment to address optimal treatment (surgical versus nonsurgical) by fracture site in patients with chronic SCI is needed.

\section{DATA ARCHIVING}

There were no data to deposit.

\section{CONFLICT OF INTEREST}

The authors declare no conflict of interest.

\section{ACKNOWLEDGEMENTS}

This study was supported by grants from the VA Health Services Research and Development Program (VA Merit Review IIR 11-103-3) and the Rheumatology Research Foundation (Ephraim P. Engleman Resident Preceptorship Award).

\section{DISCLAIMER}

This work does not reflect the views of the Veterans Health Administration or the United States government.

1 Selvarajah S, Hammond ER, Haider AH, Abularrage CJ, Becker D, Dhiman N et al. The burden of acute traumatic spinal cord injury among adults in the united states: an update. J Neurotrauma 2014; 31: 228-238.

2 Jiang SD, Jiang LS, Dai LY. Mechanisms of osteoporosis in spinal cord injury. Clin Endocrinol(Oxf) 2006; 65: 555-565.

3 Charmetant C, Phaner V, Condemine A, Calmels P. Diagnosis and treatment of osteoporosis in spinal cord injury patients: a literature review. Ann Phys Rehabil Med 2010; 53: 655.

4 Fattal C, Mariano-Goulart D, Thomas E, Rouays-Mabit H, Verollet C, Maimoun L. Osteoporosis in persons with spinal cord injury: the need for a targeted therapeutic education. Arch Phys Med Rehabil 2011; 92: 59-67.

5 Phonthee S, Saengsuwan J, Siritaratiwat W, Amatachaya S. Incidence and factors associated with falls in independent ambulatory individuals with spinal cord injury: a 6-month prospective study. Phys Ther 2013; 93: 1061-1072.

6 Carbone LD, Chin AS, Burns SP, Svircev JN, Hoenig H, Heggeness M et al. Morbidity following lower extremity fractures in men with spinal cord injury. Osteoporos/nt 2013, 24: 2261-2267.

7 Eichenholtz SN. Management of Long-bone Fractures in Paraplegic Patients. J Bone Joint Surg 1963; 45- A: 299-310.
8 Ragnarsson KT, Sell GH. Lower extremity fractures after spinal cord injury: a retrospective study. Arch Phys Med Rehabil 1981; 62: 418-423.

9 Freehafer AA, Hazel CM, Becker CL. Lower extremity fractures in patients with spinal cord injury. Paraplegia 1981; 19: 367-372.

10 Ingram RR, Suman RK, Freeman PA. Lower limb fractures in the chronic spinal cord injured patient. Paraplegia 1989; 27: 133-139.

11 Barlehner CBVFRMT. Surgery for fractures of the lower extremities in cases of chronic spinal cord injury. Orthopade 2005; 34.:137.

12 Meiners T, Keil M, Flieger R, Abel R. Use of the ring fixator in the treatment of fractures of the lower extremity in long-term paraplegic and tetraplegic patients. Spinal Cord. 2003; 41: 172-177.

13 Smith BM, Evans CT, Ullrich P, Burns S, Guihan M, Miskevics S et al. Using VA data for research in persons with spinal cord injuries and disorders: lessons from SCI QUERI. J Rehabil Res Dev 2010; 47: 679-688.

14 Garland DE, Stewart CA, Adkins RH, Hu SS, Rosen C, Liotta FJ et al. Osteoporosis after spinal cord injury. J Orthop Res 1992; 10: 371-378.

15 National Center for Health S. The International Classification of Diseases: 9th Revision, Clinical Modification: ICD-9-CM: US Department of Health and Human Services Public Health Service Health Care Financing Administration 1989.

16 Logan Jr WC, Sloane R, Lyles KW, Goldstein B, Hoenig HM. Incidence of fractures in a cohort of veterans with chronic multiple sclerosis or traumatic spinal cord injury. Arch Phys Med Rehabil 2008; 89: 237-243.

17 Merion M. Assigning E Codes for External Causes King of Prussia. PA: Merion Matters. 2007 [updated April 13, 2007 February 20, 2014]. Available from http://healthinformation.advanceweb.com/Article/Assigning-E-Codes-for-External-Causes-1.aspx.

18 Garland DE. Clinical observations on fractures and heterotopic ossification in the spinal cord and traumatic brain injured populations. Clin Orthop Relat Res 1988; 233: 86-101.

19 Dalyan M, Sherman A, Cardenas DD. Factors associated with contractures in acute spinal cord injury. Spinal Cord 1998; 36: 405-408.

20 Vanden Bossche L, Vanderstraeten G. Heterotopic ossification: a review. J Rehabil Med 2005; 37: 129-136

21 Chalmers J, Gray DH, Rush J. Observations on the induction of bone in soft tissues. JBone Joint SurgBr 1975; 57: 36-45.

22 van Kuijk AA, Geurts AC, van Kuppevelt HJ. Neurogenic heterotopic ossification in spinal cord injury. Spinal Cord 2002; 40: 313-326.

23 Sullivan MP, Torres SJ, Mehta S, Ahn J. Heterotopic ossification after central nervous system trauma: A current review. Bone Joint Res 2013; 2: 51-57.

24 Vestergaard P, Krogh K, Rejnmark L, Mosekilde L. Fracture rates and risk factors for fractures in patients with spinal cord injury. Spinal Cord. 1998; 36: 790-796.

25 Chin KR, Altman DT, Altman GT, Mitchell TM, Tomford WW, Lhowe DW. Retrograde nailing of femur fractures in patients with myelopathy and who are nonambulatory. Clin Orthop Relat Res 2000; 373: 218-226.

26 Bishop JA, Suarez P, Diponio L, Ota D, Curtin CM. Surgical versus nonsurgical treatment of femur fractures in people with spinal cord injury: an administrative analysis of risks. Arch Phys Med Rehabil 2013; 94: 2357-2364.

27 Freehafer AA, Mast WA. Lower extremity fractures in patients with spinal-cord injury. J Bone Joint Surg Am 1965; 47: 683-694.

28 Cochran TP, Bayley JC, Smith M. Lower extremity fractures in paraplegics: pattern, treatment, and functional results. J Spinal Disord 1988; 1: 219-223.

29 Sobel M, Lyden JP. Long bone fracture in a spinal-cord-injured patient: complication of treatment-a case report and review of the literature. J Trauma 1991; 31: 1440-1444.

30 Zuckerman JD. Hip fracture. N Engl J Med 1996; 334: 1519-1525.

31 Handoll HH, Parker MJ. Conservative versus operative treatment for hip fractures in adults. Cochrane Database Syst Rev 2008; 3: 1-19.

32 Sugi MT, Davidovitch R, Montero N, Nobel T, Egol KA. Treatment of lower-extremity long-bone fractures in active, nonambulatory, wheelchair-bound patients. Orthopedics 2012; 35: 1376-1382.

33 Comarr $\mathrm{AE}$, Hutchinson $\mathrm{RH}$, Bors $\mathrm{E}$. Extremity fractures of patients with spinal cord injuries. Am J Surg 1962; 103: 732-739.

34 Uehara K, Akai M, Kubo T, Yamasaki N, Okuma Y, Tobimatsu Y et al. Soft-plastic brace for lower limb fractures in patients with spinal cord injury. Spinal Cord 2013; 51: 327-330.

35 Shackelford M, Farley T, Vines CL. A comparison of women and men with spinal cord injury. Spinal Cord 1998; 36: 337-339. 